\title{
Deposição de Calda de Pulverização sobre Plantas de Salvínia em Função de pontas de Pulverização e ArRanjos populacionais entre Plantas de Aguapé e Alface-D'Água ${ }^{1}$
}

\author{
Spray Deposition on Water Fern Plants in Function of Nozzle Tips and Population Arrangements \\ with Water Hyacinth and Water Lettuce Plants
}

\author{
MARCHI, S.R. ${ }^{2}$, MARTINS, D. ${ }^{3}$, COSTA, N.V. ${ }^{4}$, CARBONARI, C.A. ${ }^{4}$ e SILVA, J.R.V. ${ }^{5}$
}

\begin{abstract}
RESUMO - Este trabalho teve como objetivo avaliar o depósito de calda pulverizada por dois tipos de pontas de pulverização sobre plantas de Salvinia auriculata dispostas em diferentes arranjos populacionais com plantas de Eichhornia crassipes e Pistia stratiotes. Um experimento foi conduzido em condições de caixas-d'água em delineamento inteiramente casualizado, com quatro repetições. Os tratamentos foram dispostos em esquema fatorial $2 \times 8$, sendo dois tipos de pontas de pulverização (ConeJet TXVK-8 e TeeJet DG 11002 VS) e oito proporções entre as plantas aquáticas, a saber: dominância total da área de cobertura da caixa-d'água pelas plantas de salvínia (100\%); e as proporções entre plantas de salvínia e de aguapé ou alface-d'água a 75\%:25\%, 50\%:50\% e 25\%:75\%. Também foi utilizada uma densidade tripla, na qual as três espécies estiveram igualmente dispostas na proporção de 33\%. Soluções dos corantes Amarelo Tartrasina FDC-5 a 3.500 ppm e Azul Brilhante FDC-1 a 1.000 ppm foram utilizadas como traçadores para as pontas TXVK-8 e DG 11002VS, respectivamente. A pulverização das soluções foi efetuada na mesma unidade experimental, com intervalo de 30 minutos entre si, com auxílio de um pulverizador costal pressurizado com $\mathrm{CO}_{2}$, calibrado de modo que proporcionasse volume de aplicação aproximado de $200 \mathrm{~L} \mathrm{ha}^{-1}$. Não foram observadas diferenças estatísticas entre os tipos de pontas de pulverização nas diferentes proporções estudadas, exceto para depósitos totais de calda de pulverização nas plantas na condição de dominância total da salvinia, uma vez que a ponta ConeJet TXVK-8 foi superior à TeeJet DG 11002 VS. Os valores dos depósitos diminuiram com o aumento da proporção de plantas de aguapé na associação e foram na condição em que $25 \%$ de plantas de salvínia estiveram associadas a $75 \%$ de plantas de aguapé. A presença da espécie alface-d'água não influenciou a deposição de gotas sobre as folhas de salvinia.
\end{abstract}

Palavras-chave: deposição de gotas, Salvinia auriculata, Eichhornia crassipes, Pistia stratiotes, tecnologia de aplicação.

\begin{abstract}
This study aimed to evaluate two types of spray tips (ConeJet TXVK-8 and TeeJet DG 11002 VS) and the amount of spray mix deposited on Salvinia auriculata plants organized under different population arrangements with Eichhornia crassipes and Pistia stratiotes plants. In addition to a full-dominance proportion over the area, corresponding to $100 \%$ cover of the water tank by eared water moss plants, arrangements with either water hyacinth or water lettuce were made at 75\%:25\%, 50\%:50\%, and 25\%:75\%. A triple density, in which the three species were equally disposed at a 33.33\% proportion, was also used. Dye solutions of FD\&C Yellow no. 5 at 3,500 ppm and FD\&C Blue no. 1 at 1,000 ppm were used, as spraying tracers for TXVK-8 and DG 11002 VS nozzles, respectively. Both solutions were sprayed at the same plot within a 30-minute interval each, through a $\mathrm{CO}_{2}$ pressured backpack, calibrated to deliver a spray volume of around
\end{abstract}

Recebido para publicação em 29.12.2009 e na forma revisada em 18.2.2011.

2 Engo-Agro ${ }^{\circ}$., Prof., Dr., Universidade Federal de Mato Grosso - UFMT, Avenida Governador Jaime Campos, 6390 - Barra do Garcas-MT, 78600-000, <sidneimarchi.ufmt@gmail.com>; ${ }^{3}$ Engo-o-Agroo., Prof., Dr., Faculdade de Ciências Agronômicas FCA/UNESP, Dep. de Produção Vegetal-Agricultura, Fazenda Experimental Lageado, s/n, Caixa Postal 237, 18610-307 Botucatu-SP; ${ }^{4}$ Aluno de Pós-Graduação, FCA/UNESP, ${ }^{5}$ Engo-Agro․, Dr., Syngenta Proteção de Cultivo, Avenida das Nações Unidas, 18001 2oandar, 04795-900 São Paulo-SP. 
$200 \mathrm{~L} \mathrm{ha} \mathrm{a}^{-1}$. The total spray deposits were estimated in $\mathrm{mL}$ perplant and the unit deposits in $\mathrm{mL} \mathrm{cm}^{-2}$ of foliar surface. No significant differences were observed between the nozzle tips used at different population arrangements, except total spray mix deposited on plants at $100 \%$ of eared water moss dominance proportion, with ConeJet TXVK-8, providing superior spray mix deposition, compared with TeeJet DG 11002 VS. The highest spray mix deposition was obtained under $100 \%$ of salvinia dominance. However, the spray mix quantity decreased with increase of water hyacinth in the proportion and reached the lowest value when $25 \%$ of eared water moss plants were associated with $75 \%$ of water hyacinth plants. The presence of water lettuce did not influence spray mix deposition over eared water moss plants.

Keywords: drop deposition, Salvinia auriculata, Eichhornia crassipes, Pistia stratiotes, spraying technology.

\section{INTRODUÇÃO}

As plantas aquáticas flutuantes são as que causam os mais sérios e difundidos problemas em nivel mundial. Elas normalmente apresentam rápida capacidade de multiplicação vegetativa, independência das estruturas sexuais de reprodução, grande área de tecido fotossintético em proporção ao comprimento da planta, rápida capacidade de ocupar locais disponiveis onde incida luz, além da independência das condições do substrato, devido ao fluxo d'água e à localização das plantas.

A $S$. auriculata (salvínia) é uma espécie da família Salviniaceae que apresenta ampla distribuição no Brasil, constituindo-se em sério problema como invasora em diferentes coleções de águas. É uma planta de águas paradas ou de pouca movimentação, e as correntezas rompem as suas estruturas devido à inexistência de lignificação de seus tecidos (Holm et al., 1991). No entanto, essa fragilidade estrutural facilita sua dispersão e a colonização de novas áreas. Essa espécie também é conhecida pela sua explosiva capacidade de colonização; em condições ótimas, forma uma enorme massa vegetativa na superficie das águas e chega a produzir 650 gramas de biomassa seca $\mathrm{m}^{-2}$ ano $^{-1}$ (Martins et al., 2002).

Geralmente, S. auriculata, E. crassipes e $P$. stratiotes são facilmente encontradas associadas nas diversas populações de plantas aquáticas, pois essas três espécies apresentam praticamente a mesma preferência quanto às condições ambientais (Holm et al., 1991). Observações realizadas em comunidades de plantas aquáticas nos reservatórios da Companhia Energética de São Paulo revelaram que $S$. auriculata, E. crassipes e P. stratiotes sempre foram citadas entre as seis espécies aquáticas de maior ocorrência e frequência nos pontos avaliados (Tanaka et al., 2002; Martins et al., 2003; Carvalho et al., 2003, 2005; Cavenaghi et al., 2005). Contudo, plantas de aguapé são altamente competitivas, tendendo a dominar o ambiente aquático e prevalecendo sobre plantas como Azolla sp., P. stratiotes, Salvinia spp., etc. (Kissmann \& Groth, 1997).

Dentre as várias possibilidades aplicáveis para o controle de plantas aquáticas, o método químico através da utilização de herbicidas representa uma opção econômica e eficaz para o manejo dessas plantas. Trabalhos realizados por diferentes pesquisadores comprovam a eficácia do controle químico nessas plantas flutuantes e sua segurança sobre organismos aquáticos por meio do uso de diversos herbicidas, como 2,4-D (Joyle \& Sikka 1977; Selvan \& Lall, 1981; Martins et al., 1999, 2002; Nelson $\&$ Shearer, 2005), glyphosate (Van et al., 1987; Martins et al., 1999, 2002; Neves et al., 2002; Lindgren et al., 1999; Fairchild et al., 2002), diquat (Martins et al., 1999, 2002), imazapyr (Martins et al., 1999, 2002), carfentrazoneethyl (Koschnick et al., 2004), entre outros.

Entretanto, alguns desses trabalhos também relatam controles insatisfatórios, os quais provavelmente podem ser atribuídos à falta de contato apropriado da calda pulverizada com as plantas (Martins et al., 2002; Neves et al., 2002). Nesse sentido, o tipo de ponta utilizada na pulverização e o arranjo entre as espécies presentes na população podem influenciar a quantidade dos depósitos de calda pulverizada sobre as plantas de salvínia, uma vez que a posição do limbo foliar, em relação à posição do limbo foliar das plantas vizinhas, pode 
favorecer ou prejudicar o contato entre a gota e a superficie foliar.

Teoricamente, folhas dispostas em posição vertical superior são mais eficientes na captura de gotas que aquelas orientadas em posição vertical inferior, o chamado "efeito guarda-chuva” (Spillman, 1984; Wirth et al., 1991; Gerard et al., 1998; Richardson \& Newton, 2000). Esse pode ser um fator determinante na deposição de calda em plantas de salvínia que convivem associadas com plantas de aguapé e alface-d'água, uma vez que seu hábito de crescimento é rente à superficie da lâmina de água e elas sempre estão em níveis inferiores quando comparadas às das outras duas espécies. Uma forma de melhorar a deposição de calda de pulverização seria a utilização de pontas que produzam maior dinâmica na gota, como as do tipo cone (Marchi et al., 2005a).

Apesar de existirem pesquisas que avaliem a eficiência dos herbicidas, ainda há pouca informação no que diz respeito à tecnologia de aplicação em ambientes aquáticos e praticamente são inexistentes informações referentes à quantificação da calda de pulverização depositada nas plantas aquáticas ou envolvendo associação entre diferentes espécies vegetais.

O presente trabalho teve o objetivo de quantificar os depósitos de calda de pulverização proporcionados pelas pontas TXVK-8 e DG 11002 VS sobre plantas de $S$. auriculata dispostas em diferentes arranjos populacionais com plantas de E. crassipes e $P$. stratiotes.

\section{MATERIAL E MÉTODOS}

Este trabalho foi conduzido no NUPAM (Núcleo de Pesquisas Avançadas em Matologia), pertencente ao Departamento de Produção Vegetal, setor de Agricultura da FCA/UNESP campus de Botucatu-SP, em delineamento inteiramente casualizado com quatro repetições, adotando-se o esquema fatorial 2 × 8 , no qual foram estudados os depósitos de calda de pulverização proporcionados por dois tipos distintos de ponta de pulverização em oito diferentes arranjos populacionais de plantas aquáticas. As unidades experimentais foram constituídas de caixas plásticas com dimensões de $45 \times 60 \times 60 \mathrm{~cm}$ e sem nenhum tipo de substrato depositado no fundo. As diferentes proporções utilizadas foram estabelecidas segundo a quantidade máxima de plantas suficiente para preencher totalmente a área superficial da unidade experimental.

As espécies utilizadas neste estudo foram: salvínia, aguapé e alface-d'água ( $S$. auriculata, $E$. crassipes e $P$. stratiotes), cujas áreas foliares médias avaliadas foram de 221,07, 21,27 e $138,48 \mathrm{~cm}^{2}$ por planta, respectivamente. Os arranjos populacionais (ou proporções) foram obtidos através da combinação entre plantas de salvínia e as outras duas espécies no mesmo reservatório, a saber: dominância total da área de cobertura da caixa-d'água pelas plantas de salvinia (100\%); e as proporções entre plantas de salvínia e de aguapé ou alface-d'água a 75\%:25\%, 50\%:50\% e 25\%:75\%. Também foi usada uma densidade tripla, em que as três espécies estiveram igualmente dispostas na proporção de 33\%. As proporções quantidades e área foliar das plantas aquáticas por unidade experimental estão apresentadas na Tabela 1.

A pulverização foi realizada por meio de pulverizador costal pressurizado com $\mathrm{CO}_{2}$, contendo barra de aplicação equipada com duas pontas de pulverização espaçadas de $50 \mathrm{~cm}$ entre si. Foram avaliados dois tipos de pontas: jato cônico ConeJet TXVK-8 e jato plano TeeJet DG 11002 VS. O equipamento foi individualmente calibrado para as duas pontas, visando a um consumo de calda de $200 \mathrm{~L} \mathrm{ha}^{-1}$, adotando-se o mesmo sentido de deslocamento para ambas as pulverizações. Os corantes, os consumos médios de calda de pulverização obtidos após a calibração de cada tipo de ponta e as condições climáticas observadas durante as aplicações encontram-se na Tabela 2.

Soluções do corante Amarelo Tartrasina FDC- 5 e do corante Azul Brilhante FDC- 1 foram utilizadas como traçadores para as pontas de pulverização, uma vez que as aplicações com ambas as pontas de pulverização foram efetuadas na mesma unidade experimental, com o objetivo de estudar quantitativamente a calda depositada nas situações distintas de pulverização em alvo único, conforme metodologia utilizada por Marchi et al. (2005a).

Adotou-se intervalo de 30 minutos entre pulverizações, o que possibilitou a secagem das gotas na superficie das folhas e possiveis 
Tabela 1 - Arranjos populacionais, número de plantas e área foliar total por espécie utilizada nas caixas-d'água para o estudo de deposição de calda de pulverização. Botucatu-SP, 2004

\begin{tabular}{|c|c|c|c|c|c|c|c|}
\hline \multirow[b]{2}{*}{ Arranjo } & \multirow{2}{*}{$\begin{array}{c}\text { Proporção } \\
(\%)\end{array}$} & \multicolumn{3}{|c|}{ Número de plantas por caixa } & \multicolumn{3}{|c|}{ Área foliar total $\left(\mathrm{cm}^{2}\right)$} \\
\hline & & Salvínia & Aguapé & $\begin{array}{l}\text { Alface- } \\
\text { d'água }\end{array}$ & Salvínia & Aguapé & $\begin{array}{l}\text { Alface- } \\
\text { d'água }\end{array}$ \\
\hline Salvínia & 100 & 180 & 0 & 0 & 24.930 & 0 & 0 \\
\hline Salvínia/aguapé & $75 / 25$ & 135 & 4 & 0 & 18.679 & 884 & 0 \\
\hline Salvínia/aguapé & $50 / 50$ & 90 & 8 & 0 & 12.465 & 1.768 & 0 \\
\hline Salvínia/aguapé & $25 / 75$ & 45 & 12 & 0 & 6.232 & 2.652 & 0 \\
\hline Salvínia/alface-d'água & $75 / 25$ & 135 & 0 & 7 & 18.679 & 0 & 149 \\
\hline Salvínia/alface-d'água & $50 / 50$ & 90 & 0 & 14 & 12.465 & 0 & 298 \\
\hline Salvínia/alface-d'água & $25 / 75$ & 45 & 0 & 21 & 6.232 & 0 & 447 \\
\hline Salvínia/aguapé/alface & $33 / 33 / 33$ & 60 & 05 & 10 & 8.310 & 1.105 & 213 \\
\hline
\end{tabular}

perdas por escorrimento da calda depositada. Deve-se ressaltar que esses corantes não influem nas características físicas da calda, como a tensão superficial das gotas pulverizadas, e não são absorvidos pelas folhas ou degradados pela luz solar por um período de até oito horas (Marchi et al., 2005b; Souza et al., 2007).

Imediatamente após a aplicação das caldas de pulverização procedeu-se à coleta e lavagem das plantas com água destilada, para retirada e recuperação dos corantes que eventualmente tenham sido depositados durante as suas respectivas aplicações. As plantas foram lavadas separadamente, utilizando-se $35 \mathrm{~mL}$ de água destilada para cada uma das espécies. As amostras obtidas foram acondicionadas em frascos plásticos de cor âmbar devidamente etiquetados e armazenados ao abrigo do calor e da luz. Posteriormente, procedeu-se à leituras de absorbância em espectrofotômetro de feixe duplo, modelo CGB Cintra 20, operando com $10 \mathrm{~mm}$ de caminho ótico no comprimento de onda de $630 \mathrm{~nm}$ para o corante Azul Brilhante FDC-1 e $427 \mathrm{~nm}$ para o corante Amarelo Tartrasina FDC-5. Os dados de absorbância foram transformados em ppm por equação matemática obtida através da leitura da absorbância de diferentes soluções-padrões de ambos os corantes, cujas concentrações (em ppm) foram previamente estipuladas.

Conhecendo as diferentes concentrações das amostras obtidas, foi possivel chegar ao volume de calda de pulverização depositada nas plantas por meio da expressão matemática

$$
C 1 . V 1=C 2 . V 2
$$

em que $C 1$ - concentração da calda de pulverização, em ppm, no momento da aplicação; $V 1$ - quantidade em $\mathrm{mL}$ que depositou nas plantas; $C 2$ - concentração da amostra, em ppm; e $V 2$ - quantidade em mL de água destilada utilizada na lavagem.

O produto dessa expressão matemática foi multiplicado por 1.000 para obtenção do volume em $\mu \mathrm{L}$. Os resultados em $\mu \mathrm{L}$ foram divididos pelas áreas foliares ou pela biomassa seca das plantas, sendo obtida a quantidade de calda de pulverização depositada em $\mu \mathrm{L} \mathrm{cm}^{2}$ e $\mu \mathrm{L}$ por planta nos diferentes arranjos estudados, respectivamente.

Tabela 2 - Corantes, consumo médio de calda de pulverização obtido após a calibração das pontas de pulverização e condições climáticas observadas durante as aplicações. Botucatu-SP, 2004

\begin{tabular}{|l|c|c|}
\hline \multirow{2}{*}{\multicolumn{1}{|c|}{ Parâmetro }} & \multicolumn{2}{c|}{ Ponta } \\
\cline { 2 - 3 } & TXVK-8 & DG 11002VS \\
\hline Classe de gotas & Fina & Grossa \\
\hline Corante & $\begin{array}{c}\text { Amarelo } \\
\text { Tartrasina FDC-5 }\end{array}$ & $\begin{array}{c}\text { Azul } \\
\text { Brilhante FDC-1 }\end{array}$ \\
\hline Consumo médio de calda & $201,9 \mathrm{~L} \mathrm{ha}^{-1}$ & $201,5 \mathrm{~L} \mathrm{ha}^{-1}$ \\
\hline Pressão de trabalho & $3,0 \mathrm{bar}$ & $2,0 \mathrm{bar}$ \\
\hline Data de aplicação & $01 / 07 / 2004$ & $01 / 07 / 2004$ \\
\hline Hora de aplicação & $8 \mathrm{~h} 30$ & $9 \mathrm{~h} 05$ \\
\hline Temperatura do ar & $21,4{ }^{\circ} \mathrm{C}$ & $21,2{ }^{\circ} \mathrm{C}$ \\
\hline Umidade relativa do ar & $63 \%$ & $66 \%$ \\
\hline Velocidade do vento & $3,1 \mathrm{~km} \mathrm{~h}^{-1}$ & $3,3 \mathrm{~km}^{-1}$ \\
\hline Ângulo jato pulverização & $90^{\circ}$ & $90^{\circ}$ \\
\hline
\end{tabular}


A área foliar das plantas de salvinia (AS) foi determinada pela equação de estimativa AS $=0,9426$ (CxL) (Marchi et al., 2004), em que $\mathrm{C}=$ comprimento ao longo da nervura principal; e $\mathrm{L}=$ largura máxima perpendicular à nervura principal.

Após obtenção da área foliar, as plantas foram acondicionadas em saco de papel e colocadas em estufa de circulação forçada de ar a uma temperatura de $60{ }^{\circ} \mathrm{C}$, até que atingissem peso constante. Posteriormente, foram pesadas em balança de precisão e obtidas suas respectivas biomassas secas.

Os resultados das quantidades de calda de pulverização depositadas nas plantas foram submetidos à análise de variância pelo teste $\mathrm{F}$, e as médias dos tratamentos, comparadas pelo teste de Tukey a 5\% de probabilidade.

\section{RESULTADOS E DISCUSSÃO}

Os maiores valores de depósitos unitários de calda de pulverização nas plantas de salvínia (Salvinia auriculata) foram obtidos na situação em que havia predominância de $100 \%$ das plantas de salvínia (Tabela 3). A presença da espécie alface-d'água não influenciou a deposição de gotas sobre as folhas de Salvinia auriculata, uma vez que os depósitos observados nas diferentes proporções estudadas não diferiram estatisticamente dos valores obtidos onde a salvinia representava $100 \%$ de domínio do ambiente aquático, independentemente do tipo de ponta de pulverização. Resultado semelhante foi obtido em estudo conduzido por Marchi et al. (2009a), os quais verificaram que as deposições de gotas proporcionadas pelas pontas TXVK-8 e DG 11002 VS sobre plantas de aguapé (Eichhornia crassipes) também não foram significativamente influenciadas quando associadas em diversas proporções com plantas de alface-d'água (Pistia stratiotes).

Entretanto, ainda nota-se que os depósitos unitários de calda de pulverização sobre as folhas de salvinia foram significativamente influenciados pela presença das plantas de aguapé. Os valores dos depósitos unitários diminuíram com o aumento da proporção de plantas de aguapé na associação, sendo menores na condição em que $25 \%$ de plantas de salvínia estiveram associadas com $75 \%$ de plantas de aguapé. Comparativamente aos valores obtidos na dominância total de plantas de salvínia, o aumento de três vezes na quantidade de plantas de aguapé na associação condicionou reduções consideráveis de $46 \%$ nos depósitos unitários de calda de pulverização proporcionados em ambas as pontas de pulverização (Tabela 3 ).

As reduções nos depósitos unitários de calda não foram devidas exclusivamente ao aumento da quantidade de plantas de aguapé

Tabela 3 - Valores médios dos depósitos unitários de calda de pulverização observados em plantas de Salvinia auriculata em função das diferentes proporções de Eichhornia crassipes e Pistia stratiotes. Botucatu-SP, 2004

\begin{tabular}{|c|c|c|c|c|c|}
\hline \multirow{2}{*}{ Arranjo } & \multirow{2}{*}{$\begin{array}{c}\text { Proporção } \\
(\%)\end{array}$} & \multicolumn{4}{|c|}{ Depósitos unitários $\left(\mu \mathrm{L} \mathrm{cm}^{-2}\right)$} \\
\hline & & TXVK-8 & Redução (\%) & DG 110.02VS & Redução (\%) \\
\hline Salvínia & 100 & $1,35 \mathrm{~A} \mathrm{a}$ & - & $1,03 \mathrm{~A} \mathrm{a}$ & - \\
\hline Salvínia/aguapé & $75 / 25$ & $1,04 \mathrm{ABC}$ a & 22,9 & $0,88 \mathrm{AB}$ a & 14,6 \\
\hline Salvínia/aguapé & $50 / 50$ & $0,91 \mathrm{BC} \mathrm{a}$ & 32,6 & $0,76 \mathrm{ABC}$ a & 26,2 \\
\hline Salvínia/aguapé & $25 / 75$ & $0,72 \mathrm{C} \mathrm{a}$ & 46,7 & $0,55 \mathrm{C} \mathrm{a}$ & 46,6 \\
\hline Salvínia/alface-d'água & $75 / 25$ & $1,20 \mathrm{AB}$ a & 11,1 & $0,99 \mathrm{AB}$ a & 3,8 \\
\hline Salvínia/alface-d'água & $50 / 50$ & $1,11 \mathrm{AB}$ a & 17,8 & $0,91 \mathrm{AB}$ a & 11,6 \\
\hline Salvínia/alface-d'água & $25 / 75$ & $1,10 \mathrm{AB}$ a & 18,5 & $0,95 \mathrm{AB}$ a & 7,8 \\
\hline Salvínia/aguapé/alface & $33 / 33 / 33$ & $0,96 \mathrm{BC} \mathrm{a}$ & 28,9 & $0,70 \mathrm{BC} \mathrm{a}$ & 32,0 \\
\hline DMS Proporção & \multicolumn{5}{|c|}{0,32} \\
\hline DMS Ponta & \multicolumn{5}{|c|}{0,41} \\
\hline $\mathrm{CV}(\%)$ & \multicolumn{5}{|c|}{24,01} \\
\hline
\end{tabular}

Médias seguidas de mesma letra, maiúscula na coluna $e$ minúscula na linha; não diferem estatisticamente entre si pelo teste de Tukey $(\mathrm{p}>0,05)$. 
na associação entre as duas espécies, e sim ao aumento de sua área foliar. Independentemente da ponta utilizada, foi constatada considerável correlação negativa entre a deposição de calda em plantas de salvínia e o aumento da área foliar das plantas de aguapé na associação, as quais foram provavelmente mais eficientes em interceptar as gotas pulverizadas antes que elas atingissem a superficie das plantas de salvínia (Figura 1).

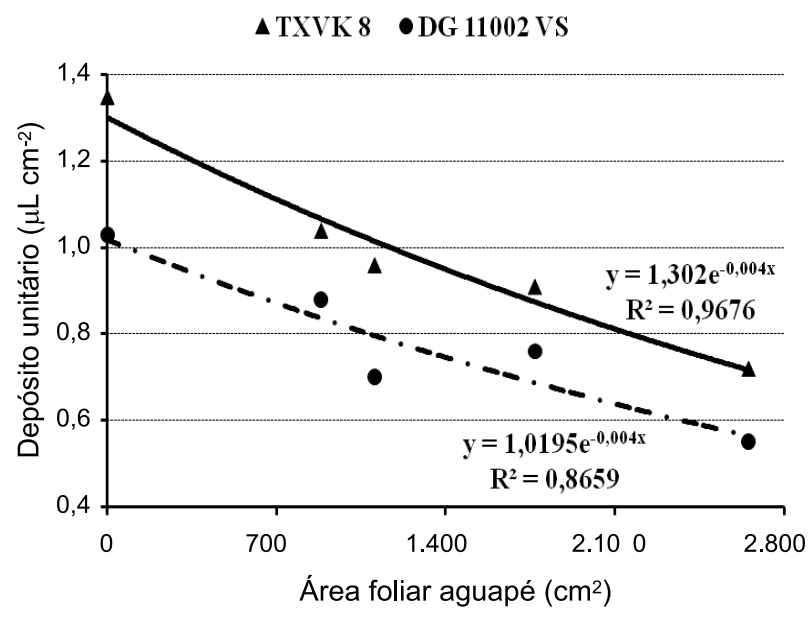

Figura 1 - Correlação entre os depósitos unitários de calda de pulverização sobre plantas de salvínia em função da área foliar total de plantas de aguapé. Botucatu-SP. 2004.
Ao contrário dos depósitos unitários, os valores dos depósitos totais de calda de pulverização não foram decisivamente influenciados pela presença de plantas de aguapé (Tabela 4). Os menores depósitos nas plantas e, consequentemente, as maiores reduções nos totais de calda de pulverização $(\mu \mathrm{L}$ por planta) novamente foram obtidos na proporção de $25 \%$ de plantas de salvinia com $75 \%$ de plantas de aguapé. Contudo, os demais valores médios de depósitos totais de calda de pulverização sobre as plantas de salvínia não diferiram estatisticamente entre si, independentemente da ponta utilizada.

Embora praticamente não tenham ocorrido diferenças significativas quanto aos depósitos totais em $\mu \mathrm{L}$ por planta, ainda na Tabela 4 é possivel notar que a porcentagem de redução observada na ponta TXVK 8 (55\%) foi relativamente superior ao valor observado para a ponta DG 11002 VS (47\%). Como as gotas pulverizadas pelas pontas tipo cone apresentam maior dinâmica quando comparadas com as pontas tipo leque (Marchi et al., 2005a), provavelmente, as folhas de aguapé interceptaram maior quantidade de calda durante a movimentação da gota e, por conseguinte, menor quantidade de calda foi depositada sobre as plantas de salvínia. Efeitos semelhantes foram observados por Marchi et al. (2009b), que, ao

Tabela 4 - Valores médios dos depósitos unitários e depósitos totais de calda de pulverização observados nas plantas de Salvinia auriculata em função das diferentes proporções de Eichhornia crassipes e Pistia stratiotes utilizadas na "Situação Salvínia". Botucatu-SP, 2004

\begin{tabular}{|c|c|c|c|c|c|}
\hline \multirow{2}{*}{ Arranjo } & \multirow{2}{*}{ Proporção (\%) } & \multicolumn{4}{|c|}{ Depósitos totais ( $\mu \mathrm{L}$ por planta) } \\
\hline & & TXVK-8 & Redução (\%) & DG 110.02VS & Redução (\%) \\
\hline Salvínia & 100 & $25,41 \mathrm{~A} \mathrm{a}$ & - & $16,70 \mathrm{~A} \mathrm{~b}$ & - \\
\hline Salvínia/aguapé & $75 / 25$ & $18,15 \mathrm{AB}$ a & 28,6 & $13,79 \mathrm{AB}$ a & 17,4 \\
\hline Salvínia/aguapé & $50 / 50$ & $18,18 \mathrm{AB}$ a & 28,4 & $12,15 \mathrm{AB}$ a & 27,2 \\
\hline Salvínia/aguapé & $25 / 75$ & $11,35 \mathrm{~B} \mathrm{a}$ & 55,3 & $8,79 \mathrm{~B} \mathrm{a}$ & 47,4 \\
\hline Salvínia/alface-d'água & $75 / 25$ & $22,53 \mathrm{~A} \mathrm{a}$ & 11,3 & $17,13 \mathrm{~A} \mathrm{a}$ & 102,6 \\
\hline Salvínia/alface-d'água & $50 / 50$ & $18,44 \mathrm{AB}$ a & 27,4 & $16,15 \mathrm{AB}$ a & 3,3 \\
\hline Salvínia/alface-d'água & $25 / 75$ & $18,66 \mathrm{AB}$ a & 26,6 & $14,50 \mathrm{AB}$ a & 13,2 \\
\hline Salvínia/aguapé/alface & $33 / 33 / 33$ & $20,34 \mathrm{~A} \mathrm{a}$ & 19,9 & $14,55 \mathrm{AB}$ a & 12,9 \\
\hline DMS Proporção & \multicolumn{5}{|c|}{8,22} \\
\hline DMS Ponta & \multicolumn{5}{|c|}{7,60} \\
\hline CV $(\%)$ & \multicolumn{5}{|c|}{32,08} \\
\hline
\end{tabular}

Médias seguidas de mesma letra, maiúscula na coluna e minúscula na linha; não diferem estatisticamente entre si pelo teste de Tukey $(\mathrm{p}>0,05)$. 
estudarem o efeito de pontas de pulverização e de arranjos populacionais de plantas de aguapé e salvínia na deposição de calda de pulverização sobre plantas de alface-d'água, também verificaram menores depósitos de calda de pulverização sobre plantas de alfaced'água quando associadas com plantas de aguapé.

Negrisoli et al. (2002), estudando depósitos unitários de calda de pulverização do corante FDC-1 com e sem surfatante Aterbane ${ }^{\circledR}$ em plantas de $S$. molesta, constataram que a adição de 5\% do surfatante reduziu quantitativamente em $1,13 \%$ os depósitos proporcionados pela ponta de pulverizaçãoXR 110.02. No entanto, a utilização de Aterbane ${ }^{\circledR}$ melhorou qualitativamente em 76,41 e $29 \%$ a deposição em 1, 5 e 10\%, respectivamente, da população com menores depósitos de corante.

Souza et al. (2007), ao estudarem o efeito da eletrização de gotas sobre a variabilidade dos depósitos de pulverização em plantas daninhas na cultura da soja, verificaram valores maiores e mais uniformes de depósitos nas plantas de $B$. plantaginea com área foliar e posições padronizadas localizadas nas entrelinhas da cultura da soja. Além disso, a proximidade com a cultura da soja não só reduziu, mas também desuniformizou os depósitos médios de calda de pulverização sobre as plantas de $B$. plantaginea, devido ao acúmulo de área foliar e efeito de sobreposição destas. Esses autores relataram ainda que em estudos comparativos de deposição de calda de pulverização é fundamental a padronização da área foliar e da posição das plantas dentro de um mesmo intervalo, o que possibilita a visualização de possíveis diferenças depositadas por plantas.

Neste estudo, a padronização da posição das folhas e plantas de salvinia foi automaticamente obtida pela disposição natural em que a planta se desenvolve na superficie da água, indicando que o aumento na proporção das plantas dessa espécie não condicionou a sobreposição intraespecífica de folhas. Ademais, a distância vertical entre as folhas da salvinia e as folhas de aguapé foi praticamente constante dentro de cada uma das proporções utilizadas. Dessa forma, as principais diferenças foram relacionadas com a proximidade horizontal entre ambas as espécies, a qual foi reduzida conforme se aumentou a proporção de aguapé na associação. Desse modo, as diferenças nas quantidades de depósitos unitários e totais de calda de pulverização observadas nas plantas de salvínia provavelmente estejam relacionadas com o acúmulo de folhas proporcionado pelo aumento da proporção de plantas de aguapé na associação e, por conseguinte, aumento da área foliar e sobreposição das plantas de salvínia - chamado efeito "guardachuva" (Spillman, 1984; Wirth et al., 1991; Gerard et al., 1998; Richardson \& Newton, 2000).

Esse resultado pode trazer relevante contribuição caso o manejo de uma população de plantas aquáticas, no qual haja predomínio das espécies salvínia, aguapé e alface-d'água, seja preferencialmente realizado utilizando-se herbicidas. A eficácia do tratamento herbicida sobre plantas de salvínia poderá ser negativamente influenciada devido à menor deposição de calda de pulverização naquelas situações ou a reboleiras, onde ocorrem maiores densidades de plantas de aguapé.

\section{LITERATURA CITADA}

CARVALHO, F. T. et al. Plantas aquáticas e nível de infestação das espécies presentes no reservatório de Barra Bonita, no rio Tietê. Planta Daninha, v. 21, n. 1, p. 15-19, 2003. Edição Especial.

CARVALHO, F. T. et al. Plantas aquáticas e nível de infestação das espécies presentes no reservatório de Bariri, no rio Tietê. Planta Daninha, v. 23, n. 2, p. 371-374, 2005.

CAVENAGHI, A. L. et al. Monitoramento de problemas com plantas aquáticas e caracterização da qualidade de água e sedimento na UHE Mogi-Guaçu. Planta Daninha, v. 23, n. 2, p. $225-231,2005$.

FAIRCHILD, J. F. et al. Efficacy of glyphosate and five surfactants for controlling giant salvinia. J. Aquatic Plant Manag., v. 40, n. 1, p. 53-57, 2002.

GERARD, A. J. M. et al. Towards predicting pesticide deposition from plant phenology; a study in spring barley. Pest. Sci., v. 53, n. 3, p. 252-262, 1998.

HOLM, L. G. et al.. The World's Worst Weeds. Malabar: Krieger Publishing Company, 1991. 609 p.

JOYLE, J. C.; SIKKA, H. C. Residual 2,4-D levels in the St. Johns River, Florida. J. Aquatic Plant Manag., v. 15, n. 2 , p. 72-82, 1977. 
KISSMANN, K.; GROTH, D. Plantas infestantes e nocivas. 2.ed. São Paulo: BASF Brasileira, 1997. Tomo I. $824 \mathrm{p}$.

KOSCHNICK, T. J. et al. Carfentrazone-ethyl pond dissipation and efficacy of floating plants. J. Plant Aquatic Manag., v. 42, n. 2, p. 103-108, 2004.

LINDGREN, C. J. et al. Compatibility of glyphosate with Galerucella calmariensis: A biological control agent for purple loosestrife (Lythrum salicaria). J. Plant Aquatic Manag., v. 37, n. 2, p. 44-48, 1999.

MARCHI, S. R. et al. Estimativa da área foliar de plantas daninhas de ambiente aquático: Salvinia auriculata. In: CONGRESSO BRASILEIRO DA CIÊNCIA DAS PLANTAS DANINHAS, 24., 2004. São Pedro. Resumo expandido... São Pedro: Sociedade Brasileira da Ciência das Plantas Daninhas, 2004. CD-ROM.

MARCHI, S. R. et al. Depósitos de calda de pulverização nas faces adaxial e abaxial de folhas de Eichhornia crassipes dispostas em diferentes ângulos. Planta Daninha, v. 23, n. 2, p. 321-328, 2005a

MARCHI, S. R. et al. Degradação luminosa e retenção foliar dos corantes Azul Brilhante FDC-1 e Amarelo Tartrasina FDC-5 utilizados como traçadores em pulverizações.

Planta Daninha, v. 23, n. 2, p. 287-294, 2005b.

MARCHI, S. R. et al. Effect of spray tips and mix deposition on comom water hyacinth growing with varied population arrangements of salvinia and water lettuce. J. Aquatic Plant Management, v. 47, n. 2, p. 110-115, 2009a.

MARCHI, S. R. et al. Efeito de pontas de pulverização e de arranjos populacionais de plantas de Eichhornia crassipes e Salvinia auriculata na deposição de calda de pulverização sobre plantas de Pistia stratiotes. Planta Daninha, v. 27, n. 2, p. 389-396, 2009b.

MARTINS, D. et al. Controle químico de plantas daninhas aquáticas em condições controladas - caixa d'água.

Planta Daninha, v. 17, n. 2, p. 289-296, 1999.

MARTINS, D. et al. Controle químico de Pistia stratiotes, Eichhornia crassipes e Salvinia molesta em caixas d'água. Planta Daninha, v. 20, p. 83-88, 2002. Edição Especial.
MARTINS, D. et al. Ocorrência de plantas aquáticas nos reservatórios da Light-RJ. Planta Daninha, v. 21, p. 105-108, 2003. Edição Especial.

NEGRISOLI, E. et al. Depósitos unitários de calda de pulverização com e sem surfatante em plantas de Salvinia molesta. Planta Daninha, v. 20, p. 51-56, 2002. Edição Especial.

NELSON, L. S.; SHEARER, J. F. 2,4-D and Mycoleptodiscus terrestris for control of eurasian watermilfoil. J. Aquatic Plant Manag., v. 43, n. 1, p. 29-33, 2005.

NEVES, T.; FOLONI, L. L.; PITELLI, R. A. Controle químico do aguapé (Eichhornia crassipes). Planta Daninha, v. 20, p. 89-97, 2002. Edição Especial.

RICHARDSON, B.; NEWTON, M. Spray deposition within plant canopies. New Zealand. Protec., v. 53, p. 248-252, 2000 .

SELVAN, R. P.; LALL, M. Chemical control of water hyacinth. In: ANNUAL CONFERENCE OF INDIAN SOCIETY OF WEED SCIENCE, 1981, Oxford. Proceedings... Oxford: 1981.p. 141-148.

SOUZA, R. T.; VELINI, E. D.; PALLADINI, L. Aspectos metodológicos para analise de depósitos de pulverizações para determinação depósitos pontuais. Planta Daninha, v. 25 , n. 1, p. $195-202,2007$

SPILLMAN, J. J. Spray impaction, retention and adhesion: an introduction to basic characteristics. Pestic. Sci., v. 15, n. 1, p. 97-106, 1984.

TANAKA, R. H. et al. Ocorrência de plantas daninhas nos reservatórios da Companhia Energética de São Paulo.

Planta Daninha, v. 20, p. 101-111, 2002. Edição Especial.

VAN, T. K. et al. Effects of herbicides rate and carrier volume on glyphosate phytotoxity. J. Aquatic Plant Manag., v. 24, n. 1, p. 66-89, 1987.

WIRTH, W.; STORP, S.; JACOBENSEN, W. Mechanisms controlling leaf retention of agricultural spray conditions Pestic. Sci., v. 31, n. 4, p. 411-420, 1991. 